\section{Effects of hyperthyroidism on expression of vascular endothelial growth factor (VEGF) and apoptosis in fetal adrenal glands}

\author{
T. Karaca, Y. Hulya Uz, R. Karabacak, \\ I. Karaboga, S. Demirtas, \\ A. Cagatay Cicek
}

University of Trakya, Faculty of Medicine, Department of Histology and

Embryology, Edirne, Turkey

\section{Abstract}

This study investigated the expression of vascular endothelial growth factor (VEGF), vascular density, and apoptosis in fetal rat adrenal glands with hyperthyroidism in late gestation. Twelve mature female Wistar albino rats with the same biological and physiological features were used for this study. Rats were divided into two groups: control and hyperthyroidism. Hyperthyroidism was induced by daily subcutaneous injections of L-thyroxine (250 $\mu \mathrm{g} / \mathrm{kg}$ ) before pregnancy for 21 days and during pregnancy. Rats in the control and hyperthyroidism groups were caged according to the number of male rats. Zero day of pregnancy (Day 0) was indicated when the animals were observed to have microscopic sperm in vaginal smears. Pregnant rats were sacrificed on the 20th day of pregnancy; blood from each animal was collected to determine the concentrations of maternal adrenocorticotropic hormone and thyroxine. Rat fetuses were then quickly removed from the uterus, and the adrenal glands of the fetuses were dissected. VEGF expression, vascular density, and apoptosis were analyzed in fetal rat adrenal glands. Maternal serum levels of the ACTH and free thyroxine were significantly higher in the hyperthyroidism group than in the control group. Immunohistochemistry revealed that the number of VEGF positive cells and vessel density significantly increased in the hyperthyroidism rat fetal adrenal group compared with the control group. Hyperthyroidism did not change the fetal and placental weights and the number of fetuses. This study demonstrates that hyperthyroidism may have an effect on the development of rat adrenal glands mediated by VEGF expression, angiogenesis, and apoptosis.

\section{Introduction}

Hyperthyroidism is a medical condition that results from an excess of thyroid hormone in the blood. The most common cause of hyper- thyroidism is Graves' disease. Hyperthyroidism significantly stimulates metabolism and causes sudden weight loss, a rapid or irregular heartbeat, sweating, and irritability. Graves' disease is prevalent in women of gestational age and affects approximately $0.2 \%$ of pregnant women. However, neonatal hyperthyroidism has been occurring in roughly $1 \%$ of neonatal born to mothers with Graves' disease. $^{1}$

In the early phases of organ development, some fetal organs are dissimilar in structural or functional organization seen in adult organs. ${ }^{2}$ The fetal adrenal systems of humans and other mammalians are structurally different from those of adult structures. ${ }^{3,4}$ The human fetal adrenal gland is composed of the definitive zone, the transitional zone, and the fetal zone, from the outer to the inner part. ${ }^{4-6}$ Conversely, the rat fetal adrenal gland is almost established around the time of birth. ${ }^{7}$ Ross et al. demonstrated that the rat adrenal cortex on gestational day 18 seems to show histological zonation, from the outer to the inner part, namely, zona glomerulosa, zona fasciculata, and zona reticularis. ${ }^{8}$ However, Mitani et al. showed the presence of a fourth zone between zona glomerulosa and zona fasciculata when performing immunohistochemical staining of an adult rat adrenal gland. ${ }^{9}$ This zone is called the undifferentiated zone and contains stem cells for the adrenal cortex.

In humans, the fetal adrenal vasculature is established by the eighth week of gestation when the adrenal gland is supplied by arteries from the descending aorta, ${ }^{6}$ and the capillaries within the organ form a continuum with a common circulation. One of the most important angiogenic factors that may be involved in the regulation of adrenal vascularization is the vascular endothelial growth factor (VEGF), the actions of which are limited to the vascular endothelial cells. VEGF is a potent regulator of blood vessel formation, and it enhances vascular permeability. ${ }^{6,10}$

CD31 [platelet endothelial cell adhesion molecule (PECAM-1)] is found on the surface of platelets, Kupffer cells, T/NK cells, and megakaryocytes, and it makes up a large portion of endothelial cell intercellular junctions. Under normal circumstances, CD31 is observed at high levels in the vascular endothelium. ${ }^{11}$

Angiogenesis and/or vasculogenesis is essential for a variety of embryonic processes, including tissue development, growth, and differentiation. Important factors act on fetal adrenal growth through intra-adrenal growth factors, and these factors include fibroblast growth factor, insulin-like growth factor II, and epidermal growth factor. ${ }^{12}$ Previous studies have suggested that extracellular components (laminin, fibronectin, and collagen IV) are also
Correspondence: Dr. Turan Karaca, University of Trakya, Faculty of Medicine, Department of Histology and Embryology, Balkan Campus, 22030 Edirne, Turkey.

Tel. +90.284 .2357653 - Fax: +90.284 .2357652 .

E-mail: turankaraca74@hotmail.com; turankaraca@trakya.edu.tr

Keywords: Hyperthyroidism; vascular endothelial growth factor; vessel density; fetal adrenal; rat.

Conflict of interest: the authors declare no conflict of interest.

Received for publication: 31 July 2015 .

Accepted for publication: 5 November 2015.

This work is licensed under a Creative Commons Attribution NonCommercial 3.0 License (CC BYNC 3.0).

(C) Copyright T. Karaca et al., 2015

Licensee PAGEPress, Italy

European Journal of Histochemistry 2015; 59:2560 doi:10.4081/ejh.2015.2560

important in coordinating proliferation, migration, and differentiation. ${ }^{13,14}$ In the present study, we investigated the expression of VEGF and CD31 in fetal rat adrenal glands with hyperthyroidism in late gestation (Day 20). We also examined the changes in apoptosis in the cortical region of fetal adrenal glands.

\section{Materials and Methods}

\section{Animals}

Twelve mature female Wistar albino rats with the same biological and physiological features were used in this study. These rats were bred in the Research Department of Experimental Animals in Trakya University, and their weights varied between 200-230 g. The study was approved by the Institutional Animal Ethical Committee of Trakya University, Edirne, Turkey (permission number: TUHDYEK-2015/23). In this experiment, all subjects were fed with rat pellet feed (Purina) containing 21\% pure protein and were given drinking water in an optimum laboratory atmosphere $\left(22 \pm 1^{\circ} \mathrm{C}, 12\right.$-h light/dark cycle).

\section{Experimental protocol}

Female rats were randomly divided into two groups: control and hyperthyroidism. Rats from the hyperthyroidism group were injected subcutaneously (sc) with $250 \mu \mathrm{g} / \mathrm{kg} /$ day of thyroxin hormone (in normal saline; L-thyroxine, Sigma, St. Louis, M0, USA) for 21 days. ${ }^{15}$ The control group received daily sc injections of a saline vehicle. After thyroxin administration for 21 days, vaginal smears were taken from 
each animal, and animals in the estrus phase were placed in a cage attached to another cage with a male rat. All females mated with males (ratio 1:1). The morning when spermatozoa were present, the vaginal smear was designated as day zero of pregnancy. ${ }^{16}$ During pregnancy, L-thyroxine was injected once every $48 \mathrm{~h}$, and the drug was stopped on the $20^{\text {th }}$ day of pregnancy. Pregnant rats were anesthetized intraperitoneally with xylazine-ketamine and sacrificed on the $20^{\text {th }}$ day of pregnancy. Blood from each animal was collected, and serum was separated to determine the concentrations of maternal ACTH and $\mathrm{T}_{4}$. Rat fetuses were then quickly removed from the uterus, and the adrenal glands of fetuses were dissected. In this study, 24 fetuses were examined for each group, and the fetuses were collected from six different mothers. The rat fetal adrenal glands were fixed with buffered formaldehyde solution for $24 \mathrm{~h}$. The fetal adrenal gland samples were dehydrated and embedded in paraffin according to standard histological procedures. Serial cross-sections of $5 \mu \mathrm{m}$ were prepared from each rat fetal adrenal gland. Fetal placental weights were also measured, and the number of fetuses was counted and recorded.

\section{Chemical immunoassay of ACTH and $\mathrm{T}_{4}$ levels}

Serum concentration levels of maternal adrenocorticotropic (ACTH) and thyroxine $\left(\mathrm{T}_{4}\right)$ in both groups were measured using $100 \mu \mathrm{L}$ samples of serum with commercially available chemical immunoassay kits (Siemens, Immulite 2000 analyzer and Advia Centaur XP, respectively).

\section{Immunohistochemical examination}

The avidin-biotin complex method was used for immunohistochemical staining as previously reported. ${ }^{17}$ Sections of $5 \mu \mathrm{m}$ thick were examined by light microscopy on the preparations obtained from each rat. The paraffin sections were incubated with specific monoclonal anti-VEGF antibodies (1:100; ab46154, Abcam, Cambridge, MA, USA). In the negative controls, the primary antibodies were replaced with phosphate-buffered saline (PBS). Fetal adrenal tissue sections were examined under light microscopy (400X). Cells with red cytoplasmic staining were considered positive, and the number of VEGF positive cells were counted in random high-power sections using a light microscope (Olympus BX51, Japan) and incorporating a software analysis system (Argenit Kameram, ver. 2.11.5.1, Istanbul, Turkey). In fetal adrenal glands, the number of VEGF positive cells in 10 random (each rat) sections was counted. All scores were converted to the number of VEGF positive cells per unit area $\left(\mathrm{mm}^{2}\right)$.

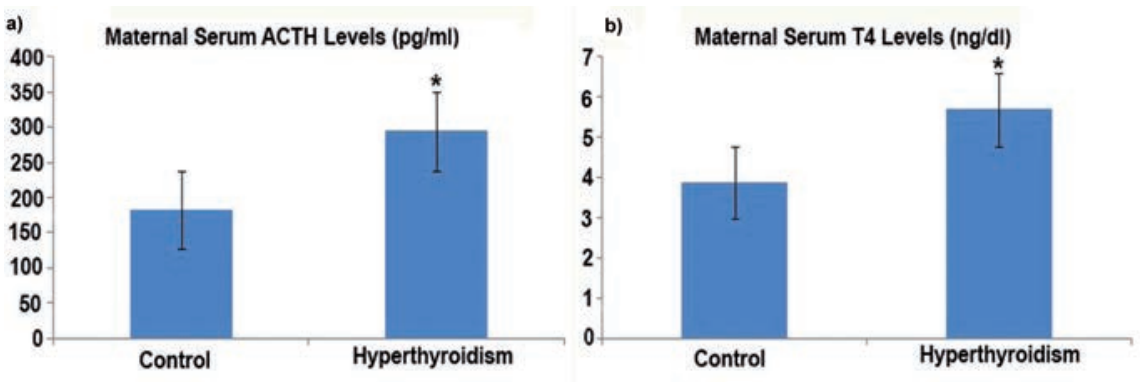

Figure 1. Effects of hyperthyroidism on maternal ACTH (a) and T4 (b) levels. ${ }^{*} \mathrm{P}<0.05$ compared with the control group.

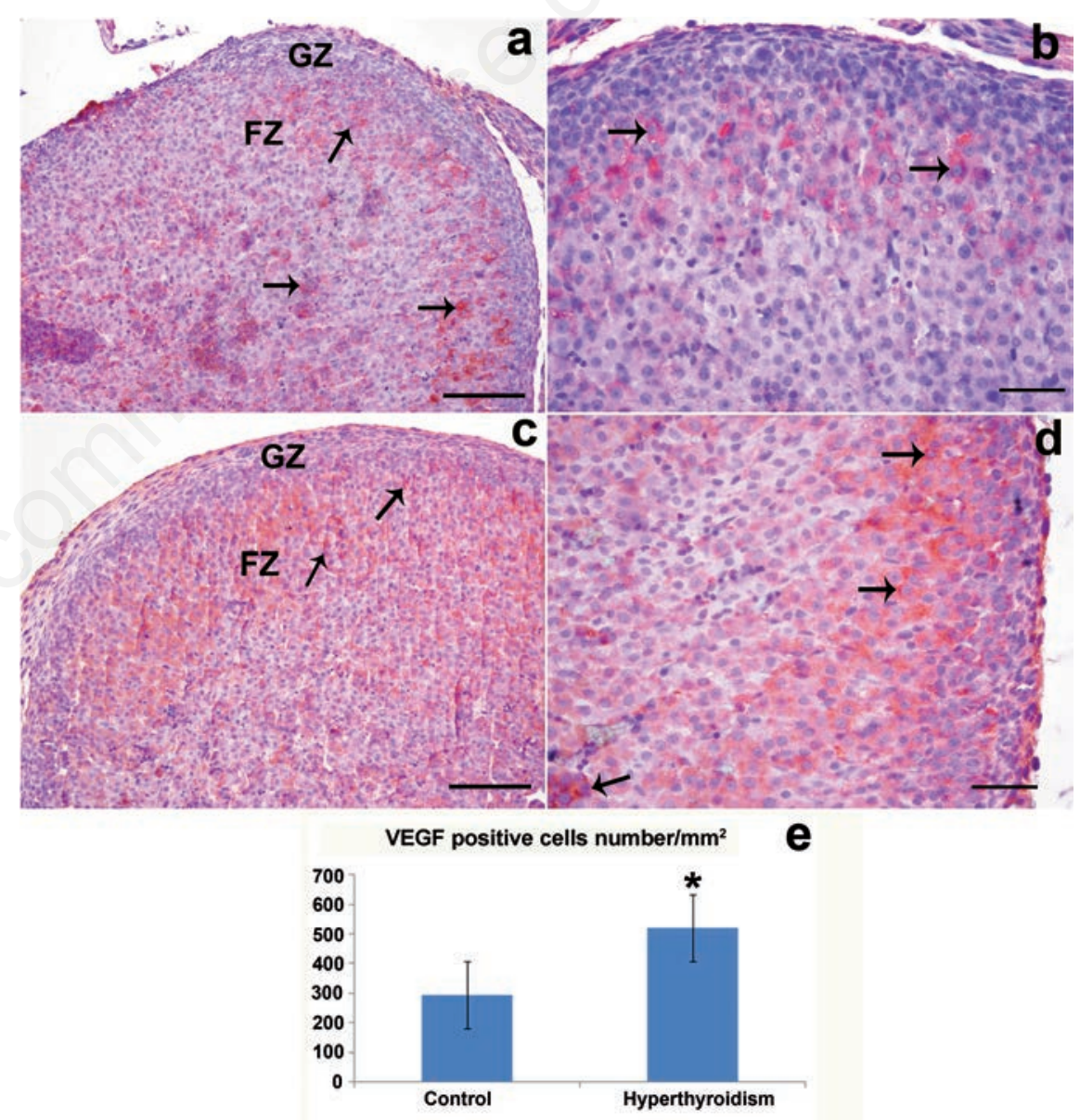

Figure 2. Expression of fetal rat adrenal VEGF in the zona glomerulosa and zona fasciculata. VEGF expression was more prominent in the zona fasciculata than in other zones in both the control and hyperthyroidism groups. a) Control group. b) Control group. c) Hyperthyroidism group. d) Hyperthyroidism group. e) Analysis of VEGF positive cells in the fetal rat adrenal gland. VEGF positive cell number in the hyperthyroidism group was significantly increased compared with the control group. GZ, zona glomerulosa; FZ, zona fasciculate; arrows, VEGF positive cells. ${ }^{*} \mathrm{P}<0.05$ compared with the control group. Scale bars: a,c) $100 \mu \mathrm{m}$; b,d) $50 \mu \mathrm{m}$. 


\section{Microvessel density}

Fetal adrenal sections were stained with the anti-CD31 (Abcam, 1:100; BS-0195R- Bioss, Woburn, MA, USA) antibodies and then analyzed. In the negative controls, the primary antibodies were replaced with PBS. ${ }^{18}$ The number of microvessels in the adrenal cortex was counted for five randomly selected fields in each section at 400x magnification. The value was defined in area $\mathrm{mm}^{2}$ for the microvessel density.

\section{TUNEL assay}

The terminal deoxynucleotidyl transferasemediated dUTP nick end labeling (TUNEL) method, which detects the fragmentation of DNA in the nucleus during apoptotic cell death in situ, was employed using an apoptosis detection kit (Apop Tag plus Peroxidase in Situ Apoptosis Detection Kit S7101, Millipore, Billerica, MA, USA), as previously reported. ${ }^{19}$ The distribution of TUNEL-positive cells was conducted in the same manner as the antiVEGF.

\section{Statistical analysis}

The statistical analyses were determined by one-way analysis of variance (ANOVA) using the SPSS version 19.0 (Chicago, IL, USA) software. Groups were compared using ANOVA with Tukey's test for post hoc analysis or by a non-parametric Kruskal-Wallis test whenever appropriate. Significance was accepted at $\mathrm{P}<0.05$.

\section{Results}

\section{Serum ACTH and $\mathrm{T}_{4}$ levels}

Both ACTH and $\mathrm{T}_{4}$ levels tended to increase in the hyperthyroidism maternal serum samples compared with the control maternal serum samples (Figure 1 a,b; $\mathrm{P}<0.05$ ). Fetal, placental weights, and number of fetuses were not significantly different between the hyperthyroidism and control rat groups (data not shown).

\section{VEGF expression}

The adrenal cortex expression of VEGF was examined by immunohistochemical staining methods. The VEGF positive cell numbers are summarized in Figure 2. The zona fasciculata contained a greater number of VEGF positive cells than the zona glomerulosa in all control and hyperthyroidism maternal offspring fetuses. In addition, the number of VEGF positive cells was higher in the outer zona fasciculata than in the inner zona fasciculata areas. The number of VEGF positive cells in the hyperthyroidism fetal group was significantly increased compared with the control fetal adrenal group (Figure 2e).

\section{Microvessel density}

The vessel density values in the hyperthyroidism group were significantly increased compared with the control fetal adrenal group. (Figure 3; $\mathrm{P}<0.05$ ). Microvessel density was more intensive in the zona glomerulosa than in the zona fasciculata (Figure 3).

\section{TUNEL assay evaluations}

The TUNEL positive cell count is summarized for both groups in Figure 4. A statistically significant increase in the number of TUNEL positive cells was detected in the hyperthyroidism group $(\mathrm{P}<0.05)$ compared with the control group. Furthermore, the TUNEL positive cell density was more intense in the zona fasciculata than in the zona glomerulosa of fetal adrenal glands (Figure 4).

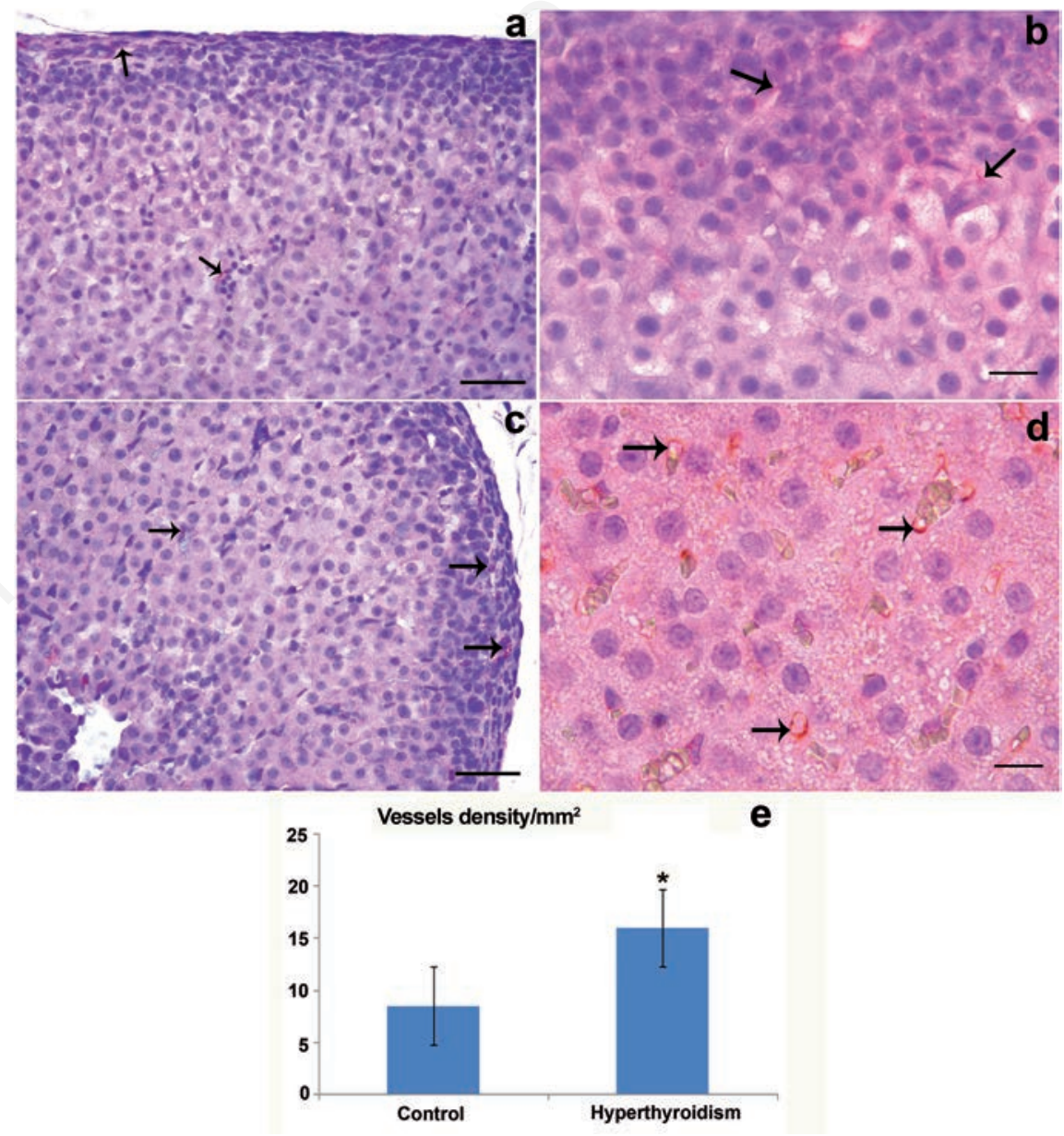

Figure 3. Anti-CD31 immunohistochemical staining. a) Control group. b) Control group. c) Hyperthyroidism group. d) Hyperthyroidism group. e) Analysis of vessel density of fetal adrenal glands. Vessel density was higher in the hyperthyroidism group than in the control group. Arrows, CD31 positive cells. ${ }^{*} \mathrm{P}<\mathbf{0 . 0 5}$ compared with the control group. Scale bars: a,c) $50 \mu \mathrm{m}$; b,d) $20 \mu \mathrm{m}$. 
were significantly increased in the hyperthyroidism group compared with the control group. ACTH secreted by the fetal pituitary plays an important role in the prominent development of the human fetal zone. ${ }^{12}$ Additionally, ACTH is the primary regulator of adult adrenal cortex trophicity. Human and other mammalian species may have developmental failures related to adrenal development-induced pathological conditions. ${ }^{12,24}$ Fetal hyperthyroidism may cause fetal tachycardia, increase in thyroid gland size, and intrauterine growth retardation..$^{25}$ In this study, hyperthyroidism (induced with L-thyroxine $250 \mu \mathrm{g} / \mathrm{kg}$ ) showed a modulatory effect on VEGF and CD31 (PECAM-1) expressions in the fetal adrenal glands. However, hyperthyroidism did not change the body weight of offspring, placental weights, and the number of fetuses (data not shown). Johnson et al. showed that adrenal weights significantly increased at 7 and 60 days in hyperthyroid rats compared with euthyroid rats. ${ }^{26}$

In previous studies, VEGF expression has been identified in human fetal adrenal glands and rhesus monkey adrenal glands. ${ }^{27}$ The expression of VEGF in the midgestation human fetal adrenal gland has been demonstrated in the definitive and fetal zones. ${ }^{27} \mathrm{We}$ demonstrated for the first time that VEGF-positive cells were denser in the periphery of the rat fetal zona fasciculata (glomerulosa-fasciculata border) in late gestation (days 20). By contrast, the number of VEGF positive cells was less in the zona glomerulosa and the central region of the fasciculata. According to a previous study, VEGF-A was expressed strongly in the glomerulosa and fasciculata layer cells in adult bovine adrenal glands. ${ }^{28}$

The human fetal adrenal gland is highly vascularized at midgestation, with a distinct patterned vascular network in the inner fetal and outer definitive zones. VEGF-positive cell density was greater in the fetal zone than in the definitive zone. Shifren et al. suggested that after the administration of ACTH, VEGF expression increased in human fetal adrenal glands. ${ }^{6}$ The nourishing effect of ACTH could be mediated through the vasculature. This argument is supported by the fact that ACTH stimulates the expression and secretion of VEGF in primary cultures of adrenal cortical cells. $^{29}$

In the literature, no study has examined the microvessel density of rat fetal adrenal gland in experimentally induced hyperthyroidism. We investigated microvessel density in fetal adrenal glands in both the zona glomerulosa and the zona fasciculate using immunohistochemistry. In this study, vascular density in the hyperthyroidism group was significantly increased in fetal adrenal tissue compared with normal healthy fetus. Terada suggested that the human fetal adrenal cortex was negative for CD31 at week 7 of gestation. ${ }^{30}$ In the current study, microvessel density immunohistochemistry revealed that the vessels were denser in the zona glomerulosa than in the zona fasciculata. We observed that hyperthyroidism increased vascular density of the fetal adrenal glands in rats. This condition may be associated with the increased maternal blood levels of ACTH, which increases vascularization. Muench et al. suggested that human fetal adrenal cells were 6\% CD31 positive in all cell populations, positive cells and vessels were observed in the capsule, and cells were dispersed in the definitive zone. ${ }^{2}$ A previous study found that capillary activities were not detected on day 16 of gestation in the rat fetal adrenal gland. ${ }^{7}$ However, the same study showed that the capillaries were detected immunohistochemically in the rat fetal adrenal gland on gestational days 19 and 20 .

Apoptosis has a critical role in the development of adrenal glands, and the disruption of developmental apoptosis may produce conditions such as hyperthyroidism and steroidogenic hormone secretion disorders. ${ }^{31}$ In the present study, fetal adrenal glands of the hyperthyroidism group showed higher numbers of apoptotic cells than the control group glands. In both groups, the TUNEL positive cells were particularly found in the inner region of the zona fasciculata. Spencer et al. suggested that human fetal adrenal apoptotic cells were detected at low levels in the definitive zone. ${ }^{31}$ In the present study, TUNEL positive cells, regardless of the group, were rarely observed in the zona glomerulosa of fetal rat adrenal glands. The number of apoptotic cells was low in the control fetal adrenal glands at day 20 of gestation, but it increased markedly in the fetal adrenal tissue of the hyperthyroidism rat group. These results are similar to those of previous studies. For example, Jirasek detected cellular apoptosis in human fetal adrenal glands, mainly in the central portions of the fetal zone. ${ }^{32}$ Mitani et al. suggested that apoptosis was scattered during the late gestational period in the rat fetal adrenal gland. ${ }^{7}$

Previous studies have suggested that fetal pituitary ACTH is required for normal adrenal growth. However, fetal zone regression and the postnatal involution of the adrenal gland do not coincide with an apparent decrease in ACTH exposure. ${ }^{31,33}$ With regard to fetal zone regression and cell apoptosis, the current thinking is that other factors, such as the peptides activin A and TGF , can stimulate apoptosis in several cell types. ${ }^{34,35}$

We demonstrated changes in the distribution of VEGF expression, microvessel density, and apoptosis in the rat fetal adrenal gland after L-thyroxine-induced experimental hyperthyroidism. An abundance of VEGF protein expression was found on the outer side of the zona fasciculata in the rat fetal adrenal gland in the offspring of hyperthyroid mothers. Microvessels were dense in the capsule and in the zona glomerulosa in the hyperthyroidism group compared with the control group. These issues may be clarified by a detailed investigation of the development of adrenal gland cells during fetal growth.

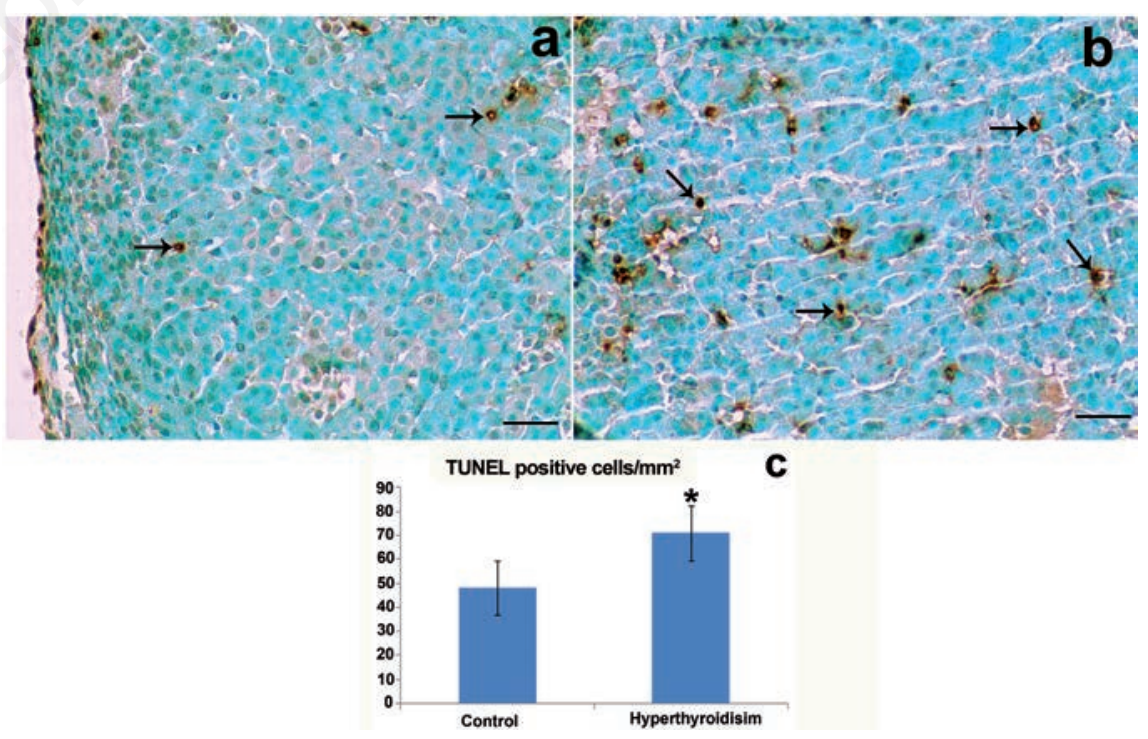

Figure 4. Representative photographs of the TUNEL assay. a) Control group. b) Hyperthyroidism group. c) The number of TUNEL positive cells per $\mathbf{m m}^{2}$ was counted in the zona glomerulosa and zona fasciculata of each group. Arrows, TUNEL positive cells. ${ }^{*} \mathbf{P}<\mathbf{0 . 0 5}$ compared with the control group. Scale bars: $50 \mu \mathrm{m}$. 


\section{References}

1. Polak M, Le Gac I, Vuillard E, Guibourdenche J, Leger J, Toubert ME, et al. Fetal and neonatal thyroid function in relation to maternal Graves' disease. Best Pract Res Clin Endocrinol Metab 2004;18:289-302.

2. Muench MO, Ratcliffe JV, Nakanishi M, Ishimoto $\mathrm{H}$, Jaffe RB. Isolation of definitive zone and chromaffin cells based upon expression of CD56 (neural cell adhesion molecule) in the human fetal adrenal gland. J Clin Endocrinol Metab 2003;88: 3921-30.

3. Jaffe RB, Seron-Ferre M, Crickard K, Koritnik D, Mitchell BF, Huhtaniemi IT. Regulation and function of the primate fetal adrenal gland and gonad. Recent Prog Horm Res 1981;37:41-103.

4. Rainey WE, Rehman KS, Carr BR. Fetal and maternal adrenals in human pregnancy. Obstet Gynecol Clin North Am 2004;31:817-35.

5. Chung HR. Adrenal and thyroid function in the fetus and preterm infant. Korean $\mathbf{J}$ Pediatr 2014;57:425-33.

6. Shifren JL, Mesiano S, Taylor RN, Ferrara N, Jaffe RB. Corticotropin regulates vascular endothelial growth factor expression in human fetal adrenal cortical cells. J Clin Endocrinol Metab 1998;83:1342-7.

7. Mitani F, Mukai K, Miyamoto H, Suematsu M, Ishimura Y. Development of functional zonation in the rat adrenal cortex. Endocrinology 1999;140:3342-53.

8. Roos TB. Steroid synthesis in embryonic and fetal rat adrenal tissue. Endocrinology 1957;81:716-28.

9. Mitani F, Suzuki H, Hata J, Ogishima T, Shimada H, Ishimura Y. A novel cell layer without corticosteroid-synthesizing enzymes in rat adrenal cortex: Histochemical detection and possible physiological role. Endocrinology 1994; 135:431-8.

10. Jégou S, El Ghazi F, De Lendeu PK, Marret S, Laudenbach V, Uguen A, et al. Prenatal alcohol exposure affects vasculature development in the neonatal brain. Ann Neurol 2012;72:952-60.

11. Newman PJ, Berndt MC, Gorski J, White GC 2nd, Lyman S, Paddock C, Muller WA. PECAM-1 (CD31) cloning and relation to adhesion molecules of the immunoglobulin gene superfamily. Science 1990;247: 1912-22.

12. Coulter CL. Fetal adrenal development: insight gained from adrenal tumors.
Trends Endocrinol Metab 2005;16:235-242.

13. Aplin AE, Howe A, Alahari SK, Juliano RL. Signal transduction and signal modulation by cell adhesion receptors. The role of integrins, cadherins, immunoglobulin-cell adhesion molecules, and selectins. Pharmacol Rev 1998;50:197-263.

14. Giancotti FG, Ruoslahti E. Integrin signaling. Science 1999;285;1028-32.

15. Noll B, Göke B, Willemer S, Richter G, Arnold R. Influence of experimental hyperthyroidism on blood and myocardial serotonin in rats. Res Exp Med (Berl) 1988;188:433-42.

16. Koh PO, Sung JH, Won CK, Cho JH, Moon JG,Park OS, Kim MO. Streptozotocininduced diabetes decreases placenta growth factor (PIGF) levels in rat placenta. J Vet Med Sci 2007;69:877-80.

17. Gencer M, Karaca T, Güngör AN, Hacıvelioğlu SÖ, Demirtaş S, Turkon H, et al. The protective effect of quercetin on IMA levels and apoptosis in experimental ovarian ischemia-reperfusion injury. Eur J Obstet Gynecol Reprod Biol 2014;177:13540.

18. Sağıroglu T, Sayhan MB, Yağci MA, Yalta T, Sağıroğlu G, Çopuroğlu E, Oğuz S Comparison of sirolimus and colchicine treatment on the development of peritoneal fibrozis in rats having peritoneal dialysis. Balkan Med J 2015;32:101-6.

19. Gungor ANC, Gencer M, Karaca T, Hacivelioglu S, Uysal A, Korkmaz F, et al. The effect of hesperetin on ischemiareperfusion injury in rat ovary. Arch Gynecol Obstet 2014;290:763-9.

20. Ishimoto H, Ginzinger DG, Jaffe RB. Adrenocorticotropin preferentially up-regulates angiopoietin 2 in the human fetal adrenal gland: implications for coordinated adrenal organ growth and angiogenesis. J Clin Endocrinol Metab 2006;91:190915.

21. McClellan M, Brenner RM. Development of the fetal adrenals in nonhuman primates: electron microscopy. In: Novy MJ, Resko JA (eds.) Fetal endocrinology. New York: Academic Press, 1981;383-403.

22. Leger J, Olivieri A, Donaldson M, Torresani T, Krude H, van Vliet G, et al. European Society for Paediatric Endocrinology consensus guidelines on screening, diagnosis, and management of congenital hypothyroidism. J Clin Endocrinol Metab 2014;99:363-84.

23. Rosol TJ, Yarrington JT, Latendresse J, Capen CC. Adrenal gland: structure, function, and mechanisms of toxicity. Toxicol Pathol 2001;29:41-8.
24. Mesiano S, Jaffe RB. Developmental and functional biology of the primate fetal adrenal cortex. Endocr Rev 1997;18:378403.

25. Van Vliet G, Polak M, Ritzén EM. Treating fetal thyroid and adrenal disorders through the mother. Nat. Clin Pract Endocrinol Metab 2008;4:675-82.

26. Johnson E0, Kamilaris TC, Calogero AE, Gold PW, Chrousos GP. Experimentallyinduced hyperthyroidism is associated with activation of the rat hypothalamicpituitary - adrenal axis. Eur J Endocrinol 2005;153:177-85.

27. Ishimoto $\mathrm{H}$, Minegishi $\mathrm{K}$, Higuchi $\mathrm{T}$, Furuya M, Asai S, Kim SH, et al. The periphery of the human fetal adrenal gland is a site of angiogenesis: zonal differential expression and regulation of angiogenic factors. J Clin Endocrinol Metab 2008;93:2402-8.

28. Vittet D, Ciais D, Keramidas M, De Fraipont F, Feige JJ. Paracrine control of the adult adrenal cortex vasculature by vascular endothelial growth factor. Endocr Res 2000;26:843-52.

29. Gaillard I, Keramidas M, Liakos P, Vilgrain I, Feige JJ, Vittet D. ACTH-regulated expression of vascular endothelial growth factor in the adult bovine adrenal cortex: a possible role in the maintenance of the microvasculature. J Cell Physiol 2000;185: 226-34.

30. Terada T. Stem cells in the development and differentiation of the human adrenal glands. Microsc Res Tech 2015;78:59-64.

31. Spencer SJ, Mesiano S, Lee JY, Jaffe RB. Proliferation and apoptosis in the human adrenal cortex during the fetal and perinatal periods: implications for growth and remodeling. J Clin Endocrinol Metab 1999; $84: 1110-15$

32. Jirasek JE. Human fetal endocrines London: Martinus Nijhoff; 1980.

33. Winters AJ, Oliver C, Colston C, MacDonald PC, Porter JC. Plasma ACTH levels in the human fetus and neonate as related to age and parturition. J Clin Endocrinol Metab 1974;39:269-73.

34. Nishihara T, Ohsaki Y, Ueda N, Koseki T, Eto $\mathrm{Y}$. Induction of apoptosis in B lineage cells by activinAderived from macrophages. J Interferon Cytokine Res 1995; 15:509-16.

35. Schwall RH, Robbins K, Jardieu P, Chang L, Lai C, Terrell TG. Activin induces cell death in hepatocytes in vivo and in vitro. Hepatology 1993;18:347-56. 